\title{
Microstructural Investigation of PM-355 Nuclear Track Detector Subjected to Low-Dose Gamma Irradiation: A Positron Annihilation Lifetime Study
}

\author{
Emad Hassan Aly \\ Department of Physics, Faculty of Science, Ain Shams University, Cairo, Egypt. \\ Email: emad_h_ali@yahoo.com \\ Received June $10^{\text {th }}, 2013$; revised August $18^{\text {th }}, 2013$; accepted August $29^{\text {th }}, 2013$ \\ Copyright (C) 2013 Emad Hassan Aly. This is an open access article distributed under the Creative Commons Attribution License, \\ which permits unrestricted use, distribution, and reproduction in any medium, provided the original work is properly cited.
}

\begin{abstract}
Samples of the PM-355 polymeric solid state nuclear track detector were exposed to low gamma absorbed doses from 1 $\mathrm{kGy}(0.1 \mathrm{Mrad})$ up to $9 \mathrm{kGy}(0.9 \mathrm{Mrad})$. Positron annihilation lifetime (PAL) in conjunction with transmission electron microscopy (TEM) and Thermo-gravimetric analysis (TGA) were performed on irradiated and pristine samples at room temperature. The observed lifetime spectra were resolved into three components where the ortho-positronium (o-Ps) lifetime component was associated with the pick-off annihilation of positronium trapped by the free volume. PAL studies of irradiated PM-355 samples showed that ortho-positronium (o-Ps) lifetime increases with an increase in dose up to $4 \mathrm{kGy}$ and decreases at higher doses. In contrast, the intensity of the o-Ps component, $\mathrm{I}_{3}$, decreases with the dose up to about $2 \mathrm{kGy}$, followed by a much smooth decrease up to $7 \mathrm{kGy}$, and then it levels off. TGA analysis indicated that the PM-355 detector decomposed in one main breakdown stage. These results are discussed on the basis of chemical and physical changes occurring at the microscopic level in the PM-355 due to irradiation. Crosslinking dominates for doses between 1 and $4 \mathrm{kGy}$, while the degradation mechanism (Chain scission) prevails for doses up to $9 \mathrm{kGy}$.
\end{abstract}

Keywords: Positron Annihilation Lifetime; Nuclear Track Detector; TEM; Gamma Dose; TGA

\section{Introduction}

Polymeric materials are, at the present, extensively recognized as being of substantial meaning in a broad diversity of immense industrial and scientific interest [1]. Since radiation is one of the major factors that change the structural properties of polymers, in particular solid-state nuclear track detectors (SSNTDs), it would be meaningful to study the modification on their properties due to irradiation. Solid-state nuclear track detectors have found a variety of applications in different fields of science and technology [2]. These detectors have recently found extensive applications in plentiful high-temperature plasma experiments for corpuscular diagnostics. Diverse techniques have been applied in such studies and it has been widely established that the polymer CR-39 is a remarkably valuable radiation detector due to its capability to map out heavy ionized particles and neutrons [3-6]. An allyldiglycol polycarbonate (CR-39) plastic is one of the applicants for dosimeter material, having a dose response in an elevated gamma dose region. The particular CR-39 polymer PM-355 is of explicit concern, finding assorted applications in physical and technological sciences [7]. All versions of the detectors i.e. CR-39, PM-355 and PM-500 have identical chemical composition: $\mathrm{C}_{12} \mathrm{H}_{18} \mathrm{O}_{7}$ (polycarbonate of allyldiglycol). Differences among them are principally due to technical dealings such as additives of plasticizers, curing cycles and extrusion, quenching processes [8]. The PM-355 plastic appeared to be the most excellent one, particularly for the recognition of light ions including protons, deuterons, He-, C-, and S-ions, and consequently, this detector was principally used in the plasma experiments [9] and was suggested as an appropriate analytical tool for the laser-plasma experiment [10].

Irradiation by ionizing radiations is a distinctive and influential mean for modifying the physical properties of polymers. Radiation induces modifications in the chemical, physical and mechanical properties in the polymer material. Molecular chain scission, intermolecular crosslinking, rearrangement of bonding, and formation of carbon-rich clusters are some structural deformations in 
the irradiated polymer that direct to modify in the optical and dielectric properties of the material [11,12]. It is noticeable that the main physical interaction of radiations with the SSNTDs creates particular damage identified as chemical bond scission, free radicals and consecutive cross-linking [13]. For numerous polymers, together processes coexist and whichever one may dominate depending not only upon the chemical structure of the polymer, but also upon the circumstances of irradiation [14]. The cross-linking and main chain scissions that take place throughout irradiation possibly will lead to sharp changes in the physical properties of the polymer.

The microstructure of the sub-nanometer local freevolume holes that arise from the irregular molecular packing in polymers is largely determining the macroscopic properties of those materials. Positron annihilation lifetime spectroscopy (PALS) provides direct information about the size and numbers of microscopic holes in the polymer $[15,16]$. Therefore, in recent years, it has been used to explore the changes in the properties of irradiated polymer matrices. Positrons are injected in solid reach thermal energies in few picoseconds, and then after a diffusion path, they are trapped in open structures where they annihilate with an electron. A considerable fraction of the inserted positrons into the molecular materials, such as polymers, forms a positronium (Ps) [17] bound state. The annihilation characteristics are determined by the local electronic environment of the annihilation site. The bound state subsists both in triplet (orthopositronium, o-Ps) and in singlet (para-positronium, p-Ps) states, depending upon the spins of electron and positron, parallel or antiparallel, respectively. The comparatively long-lived ortho-positronium (o-Ps) experiences frequent collisions with molecules through which the positron of the Ps could annihilate with an electron other than its bound partner and opposite spin (pick-off annihilation). In amorphous part of polymers the o-Ps is preferentially formed and annihilated in the region of low electron density or in the so-called free volume holes $[18,19]$. This results in a exceedingly sensitive correspondence of the o-Ps pick-off rate and consequently the lifetime to the hole size $[20,21]$. The high specific trapping rate of positrons for open volumes makes positron annihilation technique a sensitive, non-destructive method for detection and characterization of open volume structures from single vacancies up to voids and porosities.

The studies of the irradiation changes taking place in the microscopic structure of materials are significant to material science. The aim of the present study is to investigate the changes induced by gamma irradiation doses from $1 \times 10^{3}$ up to $9 \times 10^{3}$ Gray on the thermalproperties and microscopic structure of PM-355 SSNTDs. The study of the free volume presented in the amorphous phase was carried out by positron annihilation lifetime spectroscopy (PALS). The different techniques in the present work permitted us to get a complete depiction of the low dose gamma irradiation effects on the investigated SSNTDs.

\section{Experimental}

The PM-355 detectors used in the present study were procured by Rohm GmbH, USA and they are declared as "super-grade" AllylDiglicol Carbonate (CR-39). Samples having the dimension $(1 \times 1) \mathrm{cm}^{2}$ and $0.3 \mathrm{~mm}$ thickness with density $\approx 0.90 \mathrm{gm} / \mathrm{cm}^{3}$ were prepared from a sheet of the super grade PM-355 detector. The chemical formula of all versions of the detectors i.e. CR-39, PM-500 and PM-355 has the same chemical composition: $\mathrm{C}_{12} \mathrm{H}_{18} \mathrm{O}_{7}$ (polyallyl-diglycol-carbonate). This formula was assumed according to the producer catalog [22]. The monomer contains two of the following functional groups; $\mathrm{CH}_{2}=$ $\mathrm{CH}-\mathrm{CH}_{2}$. Differences between the detectors are principally due to technological procedures such as additives of plasticisers, curing cycles and extrusion, quenching processes [23]. The PM-355 samples were irradiated in the presence of air using a gamma-emitting source of ${ }^{60} \mathrm{Co}$. Doses between 1 and $9 \mathrm{kGy}$ were applied at a fixed dose rate. The irradiation facility is constructed by the National Center for Radiation Research and Technology, Atomic Energy Authority of Egypt.

\subsection{PAL}

Positron lifetime measurements were then performed in these SSNTD at room temperature (about $25^{\circ} \mathrm{C}$ ) as a function of the gamma doses using a standard lifetime spectrometer, details of which are described elsewhere [24]. The principle of operation for the positron annihilation lifetime (PAL) spectrometer is to allow $\gamma-\gamma$ coincidence measurements, positron emission should be accompanied by an appropriate start signal from a nuclear de-excitation like the $1.28 \mathrm{MeV}$ photon in the case of the ${ }^{22} \mathrm{Na}$ isotope. The $511 \mathrm{keV}$ annihilation photon provides the stop signal. The PAL spectrometer consists of conventional fast-fast coincidence system with start and stop detectors, each of them made by coupling a fast (plastic) scintillator to a photomultiplier. The timing pulses are obtained by differential constant-fraction discrimination. The time delays between the start and stop signals are converted into amplitude pulses the heights of which are stored into a multichannel analyzer. Using ${ }^{22} \mathrm{Na}$, which is commercially available as an aqueous solution of ${ }^{22} \mathrm{NaCl}$, as a positron source. The source was prepared by evaporating a few drops of aqueous solution, about $15 \mu \mathrm{Ci}$, of ${ }^{22} \mathrm{NaCl}$ on a thin kapton foil of $12 \mu \mathrm{m}$ thicknesses and an area of $10 \times 10 \mathrm{~mm}^{2}$. After drying, ${ }^{22} \mathrm{NaCl}$ spots were 
covered with another similar foil and properly sealed together with epoxy glue to avoid any leakage. Positrons emitted from the source had sufficient energy $\left(\mathrm{E}_{\max }=544\right.$ $\mathrm{keV})$ to penetrate a certain depth of the sample. The source absorption by the kapton foil was about $7 \%$ and contributed to the medium lifetime components. This absorption was separated in the analysis of the lifetime spectra. The time resolution (full-width at half-maximum, FWHM) of the lifetime spectrometer was around 260 picoseconds (ps), as determined by the RESOLUTION computer code [25]. Each positron lifetime spectrum contains $10^{6}$ counts which is sufficient to be analyzed with the computer program LT 9.0 in its distribution mode. The program gave three positron lifetimes as the best variance of fit.From a semiempirical model [26], o-Ps is assumed to be localized in an infinite high potential well with the radius $r_{h}+\delta r$ where $r_{h}$ is the hole radius and $\delta r=1.66 \mathrm{~A}^{\circ}[15,20]$ describes the penetration of the Ps wave function into the hole walls. In this model the (mean) o-Ps lifetime $t_{3}=1 / \lambda_{3}=1 / \lambda_{p o}$ is used to calculate the mean radius $r_{h}\left(t_{3}\right)$ of the holes (assumed spherical) by means of the equation

$$
\lambda_{o-P o}=2 n s^{-1}\left[1-\frac{r_{h}}{r_{h}+\delta r}+\frac{1}{2 \pi} \sin \left(\frac{2 \pi r_{h}}{r_{h}+\delta r}\right)\right]
$$

where $\lambda_{p o}$ is the pick-off annihilation rate of o-Ps inside the holes. The mean hole volume follows then from $v_{h}\left(\tau_{3}\right)=(4 / 3) \pi r_{h}^{3}\left(\tau_{3}\right)$. Since the holes show a size and a shape distribution, a more reasonable way is to calculate the mean hole volume as mass centre of the hole volume distribution. LT9.0 assumes the annihilation rate distribution $\alpha_{i}(\lambda)$ of the third annihilation channel to be log normal functions. Therefore the lifetime spectrum is expressed by the Laplace transformation of the functions $\alpha_{i}(\lambda) \lambda$ where

$$
\alpha_{i}(\lambda) \lambda \mathrm{d} \lambda=\frac{1}{\sigma_{i}(2 \pi)^{\frac{1}{2}}} \exp \left[-\frac{\left(\ln \lambda-\ln \lambda_{i o}\right)^{2}}{2 \sigma_{i}^{2}}\right] \mathrm{d} \lambda
$$

and

$$
\int_{0}^{\infty} \alpha_{i}(\lambda) \lambda \mathrm{d} \lambda=1
$$

where $\sigma_{i}$ is the standard deviation of the distribution $\alpha_{i}(\lambda)$.

By determining the distribution $\alpha_{3}(\lambda)$ of the o-Ps annihilation rates and using Equation (1), the hole radius probability distribution $n\left(r_{h}\right)$ can be calculated [27,28] as:

$$
n\left(r_{h}\right)=-3.32\left\{\cos \left[\frac{2 \pi r_{h}}{\left(r_{h}+\delta r\right)}\right]-1\right\} \frac{\alpha_{3}(\lambda)}{\left(r_{h}+\delta r\right)^{2}}
$$

where $n\left(r_{h}\right)$ is the free volume holes fraction with radii between $r_{h}$ and $r_{h}+d r_{h}$. The volume fraction of free volume holes with volume between $v_{h}$ and $v_{h}+d v_{h}$ can be given by $g\left(v_{h}\right)=\frac{n\left(r_{h}\right)}{4 \pi r_{h}^{2}}$ while the fraction of holes with volume between $v_{h}$ and $v_{h}+d v_{h}$ could be given by $g_{n}\left(v_{h}\right)=\frac{g\left(v_{h}\right)}{v_{h}}$.

\subsection{TGA}

The resulting o-Ps annihilation data will be correlated with the thermogravimetric analysis (TGA) of the PM355 samples. The analysis was carried out by TGA thermogram using a DuPont thermal analysis apparatus with temperature rate of $5^{\circ} \mathrm{C} / \mathrm{min}$ and temperature range from $20^{\circ} \mathrm{C}$ to $500^{\circ} \mathrm{C}$.

\subsection{Morphological Studies}

The Conventional morphology observations of the PM355 samples were carried out by transmission electron microscopy (TEM) using JEOL JSM-1200 microscope operated at an acceleration voltage of $90 \mathrm{kV}$.

The outline of this research is exposing the PM-355 polymeric solid state nuclear track detector to low gamma radiation doses and investigate the changes induced by gamma irradiation on the microscopic structure of the PM-355 by using PAL, TGA, and TEM techniques.

\section{Results and Discussion}

\subsection{Positron Annihilation Lifetime}

All of the PAL spectra of the non-irradiated and irradiated PM-355 were analyzed assuming three discrete exponential components and the source correction due to annihilation in the source and source supporting Kapton [29]. Each lifetime corresponds to the average annihilation rate of a positron in a different state. The shortest lifetime component $\left(\tau_{1}=0.12-0.15 \mathrm{~ns}\right.$, with intensity $\mathrm{I}_{1}$ $=24 \%-43 \%$ ) is related to the self-annihilation of p-Ps, atoms, while the intermediate one $\left(\tau_{2}=0.364-0.417 \mathrm{~ns}\right.$ and $\mathrm{I}_{2}=39 \%-56 \%$ ) to annihilation of free positrons in the polymer matrix. $\tau_{2}$ is usually associated with the annihilation of positrons with valence or core electrons of the constituent atoms. The longest-lived component $\left(\tau_{3}=\right.$ $2.071-2.328$ ns and $\mathrm{I}_{3}=12.2 \%-29.2 \%$ ) is associated with annihilation of o-Ps in the intermolecular spaces of polymer structure via the pick-off annihilation [30]. Taking $\tau_{3}$ as a measure of the free volume hole size and $\mathrm{I}_{3}$ as a number of free volume holes, the lifetime of o-Ps and its intensity for the non-irradiated sample have been deduced to be $\tau_{3}=2.156 \pm 0.026$ ns and $\mathrm{I}_{3}=29.2 \% \pm 1.2 \%$. 
The positrons have a tendency to localize in comparatively more ordered regions, while Ps atoms tend to be localized in the disordered parts of a polymer matrix, and in semi-crystalline polymers Ps is localized in the amorphous regions and crystalline-amorphous interface [30].

Figure 1 shows the second lifetime $\tau_{2}$ and its relative intensity $I_{2}$ of PM-355 samples as a function of gamma dose. The middle positron lifetime $\tau_{2}$ can be connected with positron annihilation on structurally intrinsic free volume traps, such as extended vacancy-like clusters [31]. The unirradiated sample had a $\tau_{2}$ of about $402 \mathrm{ps}$, so the vacancies in the sample are called vacancy clusters [32]. It is obvious from the figure that defect lifetime $\tau_{2}$ decreases after gamma irradiation. However, the relative intensity $\mathrm{I}_{2}$ increases with increasing irradiation dose. This implies that the concentration of vacancy clusters increased after irradiation [33]. During irradiation, both vacancies and interstitials are generated. The interstitials migrate to the vacancy clusters and diminish the size of vacancy clusters, so the defect lifetime $\tau_{2}$ decreases after gamma irradiation. More supersaturated vacancies are generated with increasing irradiation dose, the vacancies migrate and agglomerate, so the concentration of vacancy cluster decreased with increasing dose from $4 \mathrm{kGy}$ up to $9 \mathrm{kGy}$.

The lifetime $\tau_{3}$ associated with the pick-off process as a function of gamma irradiation doses exhibits an increase up to $2.328 \mathrm{~ns}$ with an inflection point at the gamma dose 4 kGy as shown in Figure 2. The observed decrease in $\tau_{3}$ values with increasing dose may be attributed to a gradual formation of mobile charge carriers or

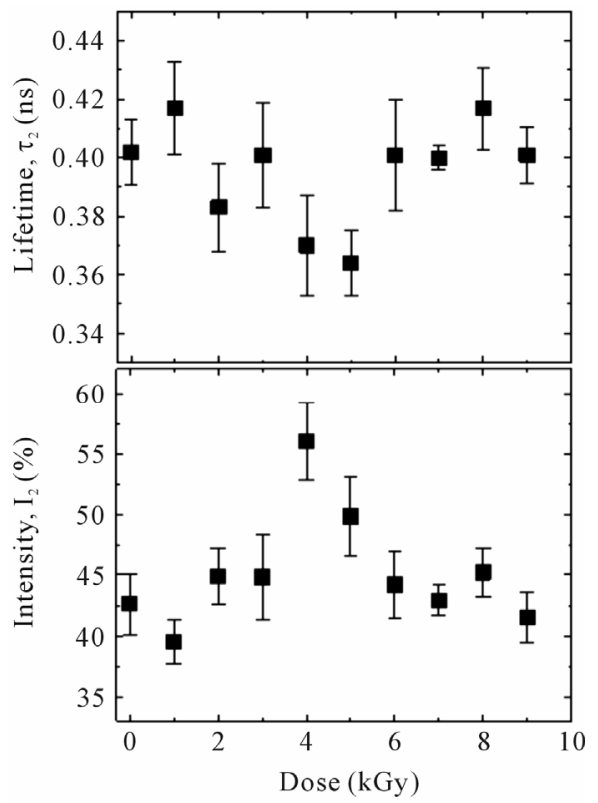

Figure 1. Variations of $\tau_{2}$ and $I_{2}$ as a function of gamma radiation dose in PM-355 polymer.

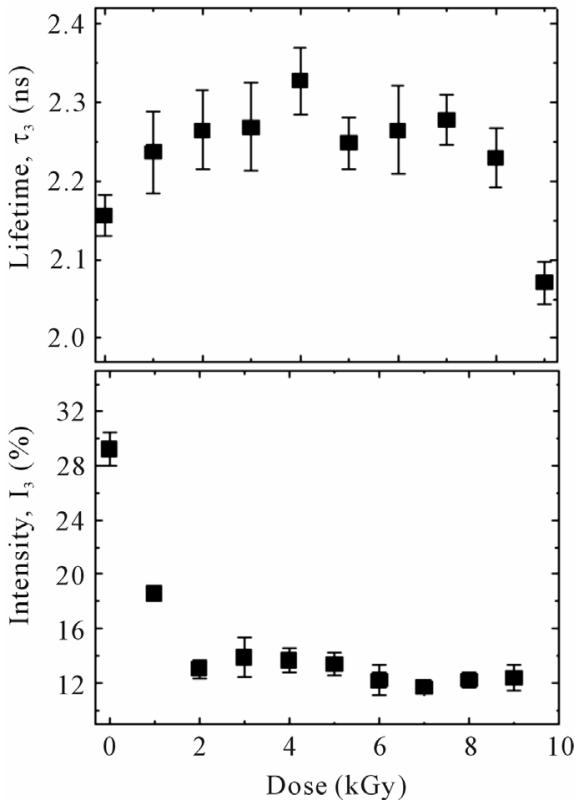

Figure 2. Variation of the o-Ps lifetime, $\tau_{3}$, and its intensity, $I_{3}$, with the irradiation dose for the PM-355 polymer.

easily orientable dipolar molecules. It is presumed that these charge carriers or dipolar molecules were formed from structural modifications (chain scission) caused by irradiation [34]. The free volumes are estimated using Equation (1) and found to decrease from 128.35 to $103.26 \AA^{3}$.

Figure 2 shows the variations of the intensity of the o-Ps lifetime component $\mathrm{I}_{3}$ for gamma irradiation processes. The variations of $\mathrm{I}_{3}$ show a rapid decrease at the beginning up to $2 \mathrm{kGy}$. This decrease in $\mathrm{I}_{3}$ at low doses reflects a decrease in the number of free volume holes seems to fit quite well with the interpretation based on the process of cross-linking of the detector molecules. At higher gamma doses the scission of the molecular chains increases [35]. With increasing dose a smooth decrease is attained up to $7 \mathrm{kGy}$ followed by leveling off up to 9 $\mathrm{kGy}$, which is familiar for $\gamma$-irradiated polymers [36]. This behavior may indicate that stability in the structure has been achieved.

It is well known that when radiation impinging a polymer matrix, it leaves a trail of damage along its track in the form of broken molecular chains and free radicals. This behavior is quite reminiscent of what is expected by recombination and promoting important chemical and structural changes in the matrix. The inhibiting effect of radiation induced free radicals in polymers has been conjectured in some occasions. This is to elucidate the decrease in $\mathrm{I}_{3}$ with dose [37]. The cross-linking might take place due to the free radical recombination and the results indicated that the changes in the polymer properties depend on whether cross-linking or degradation 
dominates during the irradiation. An increase in crystallinity is effectively observed in the irradiation process where the decrease in $\mathrm{I}_{3}$ with dose is thus attributed to this effect [15]. The variation of $\mathrm{I}_{3}$ with dose established the trend observed for $\tau_{3}$ where the decrease in $\mathrm{I}_{3}$ could be persuaded by the change in the structural effect (i.e. an increase in the crystallinity degree with increasing dose).

The PM-355 has local molecular heterogeneity structure where the positron is annihilated therefore a continuous distribution of the inverse of the longest lifetime $\left(\tau_{3}\right)$ can be obtained by analyzing the PAL spectra with the LT program. LT allows both discrete and log normal distributed annihilation rates $\lambda=1 / \tau$. From the distribution of the o-Ps annihilation rate, $\lambda_{3}=1 / \tau_{3}$, the mean size and the size distribution of free volume holes can be calculated. Figure 3(a) shows the detected positron annihilation lifetime distribution for non-irradiated and irradiated samples. For non-irradiated sample, the free volume size is distributed from 78.65 to $146.19 \AA^{3}$ (Full width at

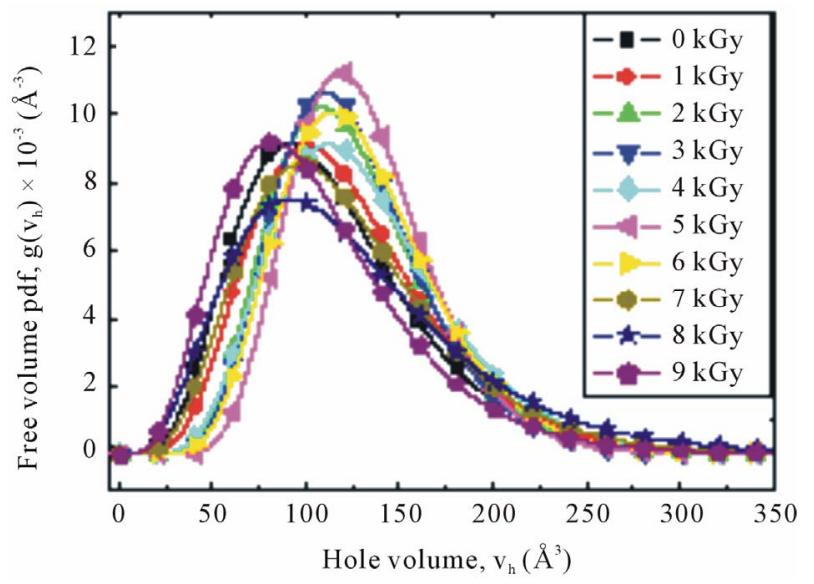

(a)

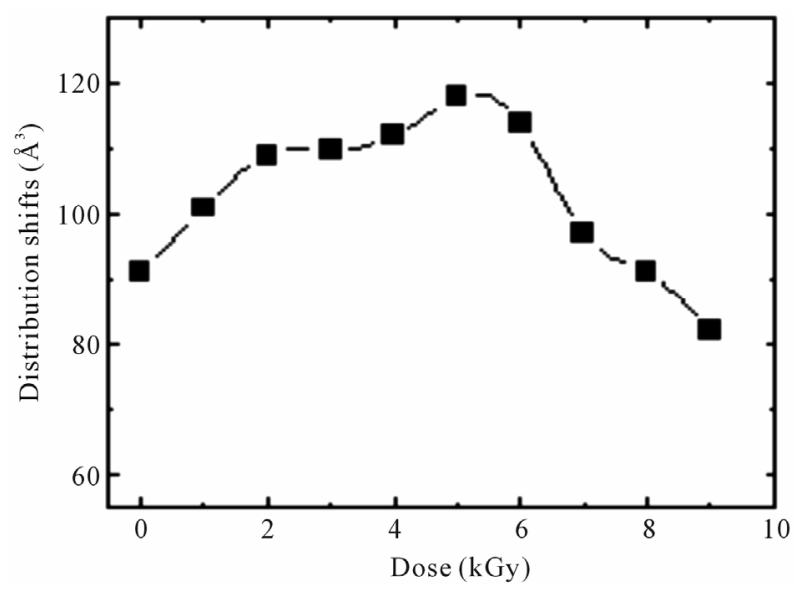

(b)

Figure 3. (a) Probability distribution function of unirradiated and irradiated PM-355 and (b) the shifts of the distribution function by gamma doses. half maximum). Due to gamma-irradiation, the distribution shifts, Figure 3(b), to higher free volume size up to $5 \mathrm{kGy}$ as a result of formation of new bonds or crosslinking which increase the o-Ps lifetime and after that the distribution shifts to lower free volume size up to $9 \mathrm{kGy}$. This is in agreement with the results obtained from the finite-term analysis.

\subsection{Thermal Gravimetric Analysis (TGA)}

To obtain a better understanding of the changes in thermal stability of PM-355 samples due to gamma irradiation TGA were performed in the temperature range from room temperature up to $500^{\circ} \mathrm{C}$, at a heating rate of $5^{\circ} \mathrm{C} \cdot \mathrm{min}^{-1}$. The TGA thermograms for non-irradiated and irradiated samples are shown in Figure 4. The values of onset temperature of decomposition $\mathrm{T}_{\mathrm{o}}$ were calculated by using these TGA thermograms, and are given in Figure 5 as a function of the gamma dose. The figure shows that $T_{0}$ increases until a maximum value at $4 \mathrm{kGy}$ irradiated sample indicating an increase in thermal stability of the polymer samples due to the cross-linking process, followed by a decrease with increase in gamma dose due to degradation (i.e. preferentially chain scission). The interpretation of these results may be that, in the dose range $1-4 \mathrm{kGy}$, the free radicals formed due to scission are chemically active and can be used in some chemical reactions that lead to the cross-linking mechanism. With increasing the gamma dose scission dominates which is reflected in a decrease in $T_{0}$ of the PM-355 samples.

\subsection{Transmission Electron Microscopy (TEM)}

The micrographs of non-irradiated PM-355 SSNTD displayed structure of a semicrystalline polymer. The crystalline regions appeared as white areas as shown in Figure 6(a). The white areas are randomly oriented and

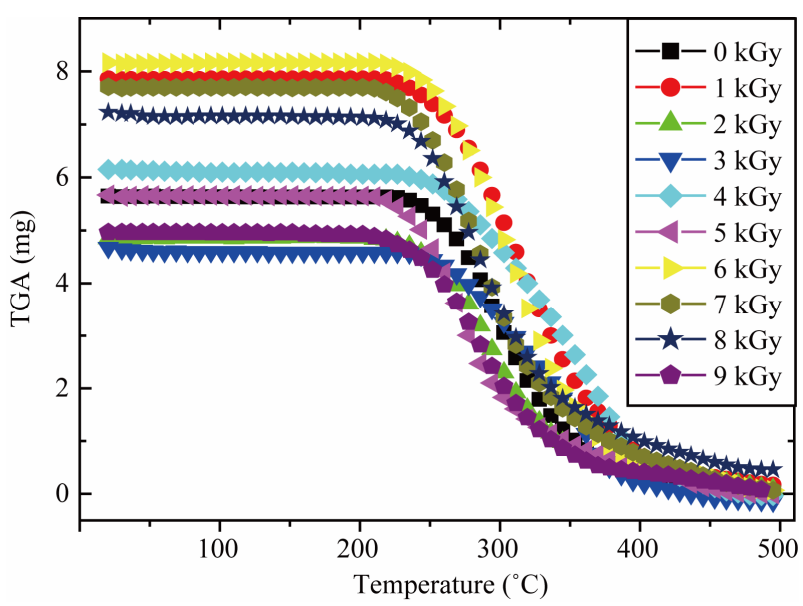

Figure 4. Thermogravimetric analysis of PM-355 as a function of gamma irradiation dose. 
separated by highly entangled polymer molecules, dark regions, which form the amorphous phase. At low doses (4 kGy), gamma irradiation generates different free radicals which causes radiolytic scission of molecular chains by cleavage of $\mathrm{C}-\mathrm{C}$ and $\mathrm{C}-\mathrm{H}$ bonds. These free radicals experience recombination (leading to crosslinking) [38]. In the proposed microstructure for this stage, the crystallinity is less than in the virgin samples which could be deduced from the $\times 15,000$ image as an increase in the dark regions concentration (see Figure 6(b)). Our TGA and PAL results on gamma-irradiated PM-355 confirm the diminution in crystallinity at $4 \mathrm{kGy}$. According to our measurements of TEM micrographs, the irradiated PM355 sample with 9 kGy dose (Figure 6(c)) showed an increase in crystallite region thickness in comparison with the $4 \mathrm{kGy}$ sample. Thus, the increase in the crystallinity produced by the irradiation dose of $9 \mathrm{kGy}$ was confirmed by the decrease in the decomposition temperature $\mathrm{T}_{\mathrm{o}}$ and the ortho-positronium lifetime $\tau_{\mathrm{o}-\mathrm{Ps}}$.

\section{Conclusion}

From the results we have reported and discussed for the gamma irradiation on TM-355 polymeric detector, our conclusions can be summarized as follows. The defect lifetime $\tau_{2}$ decreases after gamma irradiation due to interstitials migration to the vacancy clusters and diminishes the size of vacancy clusters. With increasing irradiation dose, from $4 \mathrm{kGy}$ to $9 \mathrm{kGy}$, the vacancies migrate and agglomerate, so the concentration of vacancy cluster decreases, which is confirmed by the $\mathrm{I}_{2}$ curve. The decrease of the free volumes from 128.35 to $103.26 \AA^{3}$ is attributed to a gradual formation of orientable dipolar molecules due to structural modifications (chain scission) caused by irradiation. The TGA thermograms show that the values of onset temperature of decomposition $T_{0}$ increase until a maximum value at $4 \mathrm{kGy}$ indicating an increase in thermal stability of the polymer samples. With increasing the gamma dose, scission dominates what is reflected in a decrease in $T_{0}$ of the PM-355 samples. The TEM micrographs showed an increase in crystallite region thickness with $9 \mathrm{kGy}$ dose sample in comparison with the $4 \mathrm{kGy}$ sample. This increase in the crystallinity was confirmed by the decrease in the decomposition temperature $T_{0}$ and the ortho-positronium lifetime $\tau_{\mathrm{o}-\mathrm{Ps}}$.

\section{Acknowledgements}

The author is thankful to Prof. Dr. S. A. Nouh, Ain Shams University, Faculty of Science, Physics Department

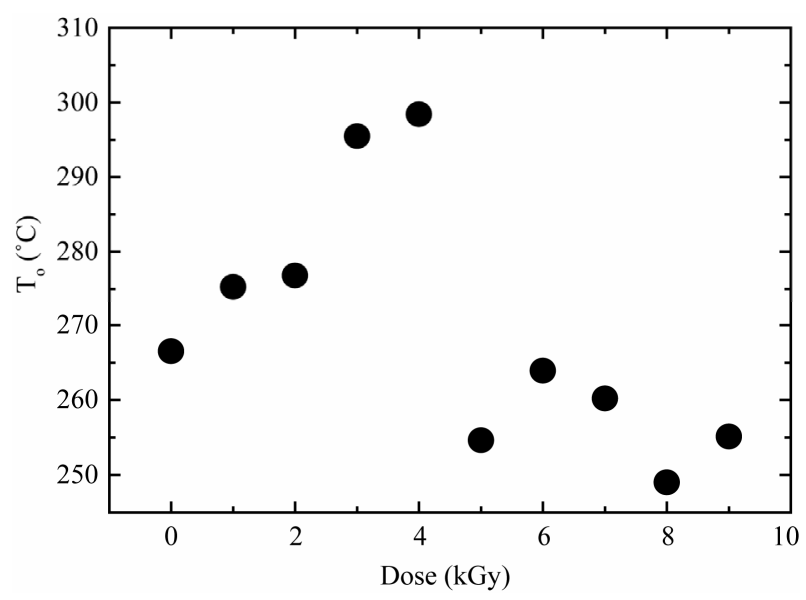

Figure 5. Effects of gamma irradiation on the decomposition temperature of PM-355.

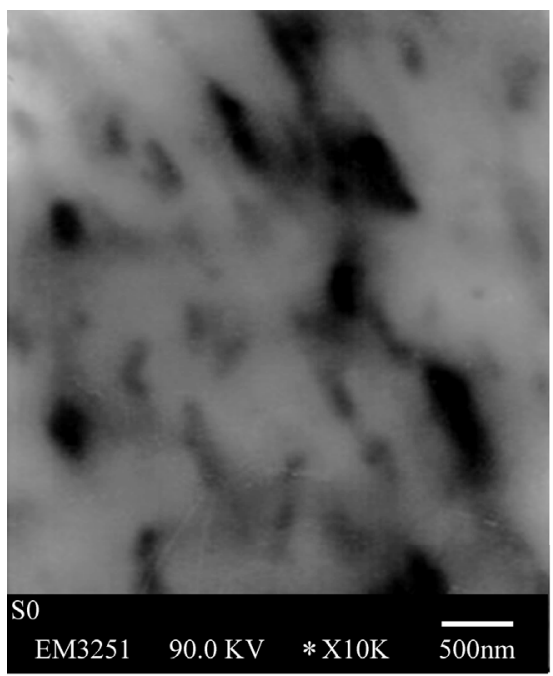

(a)

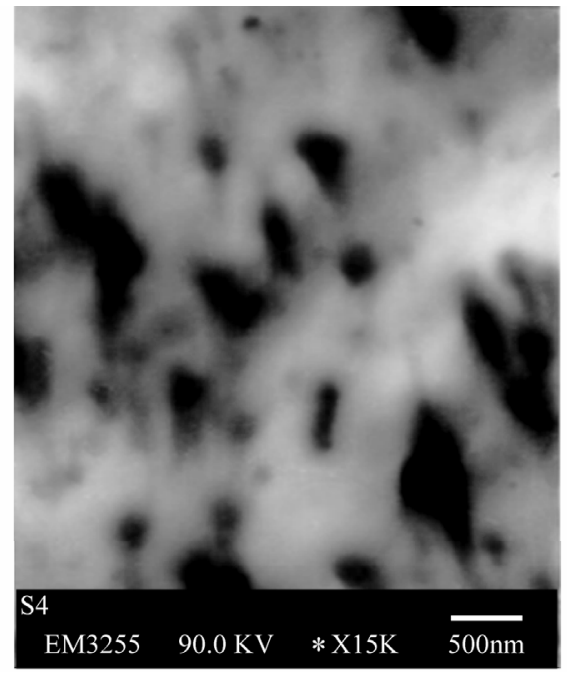

(b)

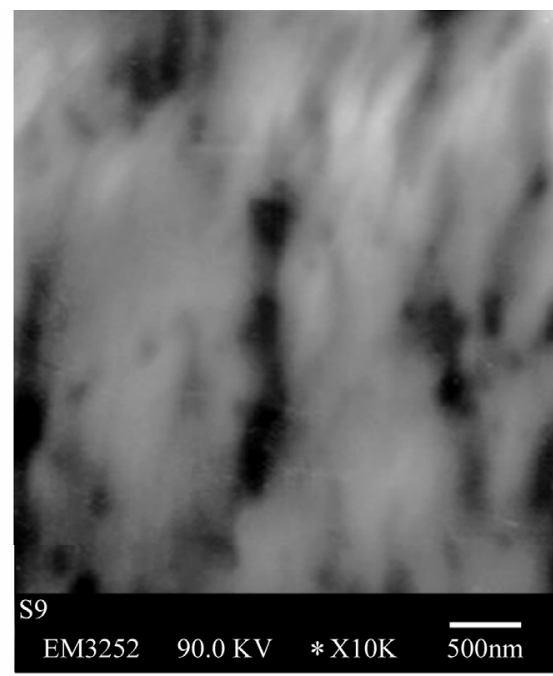

(c)

Figure 6. TEM image for (a) virgin PM-355, (b) 4 kGy gamma irradiated PM-355 and (c) 9 kGy gamma-irradiated PM-355. 
for providing the samples. Thanks are also extended to the National Center for Radiation Research and Technology, Atomic Energy Authority of Egypt for providing the irradiation facility.

\section{REFERENCES}

[1] M. Santosh, B. Dhananjay, A. Mandale, S. Gangal and V. Bhoraskar, "Electron Beam Induced surface Cross-Linking of Functional Monomers Coated on Silicon Substrate," Materials Letters, Vol. 60, No. 11, 2006, pp. 1360-1365.

http://dx.doi.org/10.1016/j.matlet.2005.11.029

[2] S. A. Durrani, "Nuclear Tracks: A Success Story of the 20th Century," Radiation Measurements, Vol. 34, No. 1-6, 2001, pp. 5-13.

http://dx.doi.org/10.1016/S1350-4487(01)00112-3

[3] W. Birkholz, C. Winkler and H. Baumbach, "Neutron Sensitivity of CR-39 SSNTD," International Journal of Radiation Applications and Instrumentation. Part D. Nuclear Tracks and Radiation Measurements, Vol. 19, No. 1-4, 1991, pp. 453-456.

[4] J. Palfalvi, "Experiences with CR-39 SSNTD in Monitoring Neutrons Emitted from Spent Reactor Fuel," International Journal of Radiation Applications and Instrumentation. Part D. Nuclear Tracks and Radiation Measurements, Vol. 19, No. 1-4, 1991, pp. 511-516.

[5] A. Gisbertz, M. Hochstrate, I. Koehler, E. Pitt and A. Scharmann, "Improvement of Response of SSNTD in Fast Neutron Dosimetry," Radiation Measurements, Vol. 28, No. 1-6, 1997, pp. 489-494. http://dx.doi.org/10.1016/S1350-4487(97)00126-1

[6] R. Pugliesi, M. Pereira, M. de-Moraes and M. de-Menezes, "Characteristics of the solid state nuclear detector CR-39 for neutron radiography purposes," Applied Radiation and Isotopes, Vol. 50, No. 2, 1999, pp. 375-380.

http://dx.doi.org/10.1016/S0969-8043(98)00092-X

[7] M. A. Anan, "Impedance Spectroscopy of Gamma Irradiated PM-355," Radiation Measurements, Vol. 41, No. 2, 2006, pp. 209-212.

http://dx.doi.org/10.1016/j.radmeas.2005.07.023

[8] S. A. Durrani and R. K. Bull, "Solid State Nuclear Track Detection. Principles, Methods and Applications," Pergamon Press, Oxford, 1987.

[9] A. Szydlowski, “Application of CR-39 Track Detectors for Corpuscular Diagnostics of High-Temperature Plasmas," Radiation Measurements, Vol. 36, No. 1-6, 2003, pp. 35-42. http://dx.doi.org/10.1016/S1350-4487(03)00095-7

[10] A. Szydlowski, J. Badziak, J. Fuchs, M. Kubkowska, P. Parys, M. Rosinski, R. Suchanska, J. Wolowski, P. Antici and A. Mancic, "Application of Solid-State Nuclear Track Detectors of the CR-39/PM-355 Type for Measurements of Energetic Protons Emitted from Plasma Produced by an Ultra-Intense Laser," Radiation Measurements, Vol. 44, No. 9-10, 2009, pp. 881-884. http://dx.doi.org/10.1016/j.radmeas.2009.08.008
[11] M. Mujahid, P. Singh, D. S. Srivastava, S. Gupta, D. K. Avasthi and D. Kanjilal, "Study of Chain Scission versus Crosslinking in MeV Ion-Irradiated Polycarbonate Using Dielectric Constant Measurements and UV Spectroscopy,' Radiation Measurements, Vol. 38, No. 1-6, 2004, pp. 197-203.

[12] S. A. Nouh, "Physical Change Associated with Gamma Doses of PM-555 Solid-State Nuclear Track Detector," Radiation Measurements, Vol. 38, No. 2, 2004, pp. 167172. http://dx.doi.org/10.1016/j.radmeas.2003.11.004

[13] M. Fromm, F. Vaginary,G. Meesen, A. Chambundet and A. Poffijn, "Watching at the Correlation between the Specific Track-Etch Rate and the Primary Physical Parameters of the Swift Ion Interaction with the CR-39," Radiation Measurements, Vol. 36, No. 1-6, 2003, pp. 93-98. http://dx.doi.org/10.1016/S1350-4487(03)00101-X

[14] D. Sinha and K. K. Dwivedi, "Radiation-Induced Modification on Thermal Properties of Different Nuclear Track Detectors," Radiation Measurements, Vol. 36, No. 1-6, 2003, pp. 713-718. http://dx.doi.org/10.1016/S1350-4487(03)00232-4

[15] H. Nakanishi, Y. C. Jean and D. M. Schrader, "Positron and Positronium Chemistry," Elsevier, Amsterdam, 1988.

[16] Q.Deng, C. S. Sunder and Y. C. Jean, "Pressure Dependence of Free-Volume Hole Properties in an Epoxy Polymer," Journal of Physical Chemistry, Vol. 96, No. 1, 1992, pp. 492-495. http://dx.doi.org/10.1021/j100180a088

[17] O. E. Mogensen, "Positron Annihilation in Chemistry," Springer-Verlag, Berlin, Heidelberg, New York, 1995. http://dx.doi.org/10.1007/978-3-642-85123-0

[18] W. Brandt, S. Berko and W. Walker, "Positronium Decay in Molecular Substances," Physical Review, Vol. 120, No. 4, 1960, pp. 1289-1295. http://dx.doi.org/10.1103/PhysRev.120.1289

[19] H. S. Sodaye, P. K. Pujari, A. Goswami and S. B. Manohar, "Probing the Microstructure of Nafion-117 Using Positron Annihilation Spectroscopy," Journal of Polymer Science Part B: Polymer Physics, Vol. 35, No. 5, 1997, pp. 771-776.

http://dx.doi.org/10.1002/(SICI)1099-0488(19970415)35: 5<771::AID-POLB5>3.0.CO;2-P

[20] M. Eldrup, D. Lightbody and J. N. Sherwood, "The Temperature Dependence of Positron Lifetimes in Solid Pivalic Acid," Chemical Physics, Vol. 63, No. 1-2, 1981, pp. 51-58. http://dx.doi.org/10.1016/0301-0104(81)80307-2

[21] H. Nakanishi, S. J. Wang, Y. C. Jean and S. C. Sharama, "Positron Annihilation Studies of Fluids," World Scientific, Singapore, 1988, pp. 292-298.

[22] P. J. McNulty, S. R. Palmer and D. D. Cooke, "Optical Properties of Particle Tracks in SSNTD Detectors," Proceedings of the 11th International Conference on SSNTD, Bristol, 7-12 September 1981, pp. 807-813.

[23] S. A. Durrani and R. K. Bull, "Solid State Nuclear Track Detection. Principles, Methods and Applications," Pergamon Press, Oxford, 1987.

[24] M. Sharma, C. Kaur, S. K. Chandramani and P. C. Jain, "Temperature-Dependent Studies in Some Homologues 
of Alkyloxycyanobiphenyls Employing Positron Lifetime Measurements," International Journal of Modern Physics, Vol. B14, No. 18, 2000, pp. 1927-1938.

[25] P. Kirkegaard, M. Eldrup, O. E. Mogensen and N. Pedersen, "Program System for Analysing Positron Lifetime Spectra and Angular Correlation Curves," Computer Physics Communications, Vol. 23, No. 3, 1981, pp. 307335. http://dx.doi.org/10.1016/0010-4655(81)90006-0

[26] S. J. Tao, "Positronium Annihilation in Molecular Substances," Journal of Chemical Physics, Vol. 56, No. 11, 1972, pp. 5499-5510. http://dx.doi.org/10.1063/1.1677067

[27] R. B. Gregory, "Free-Volume and Pore-Size Distributions Determined by PALS," Journal of Applied Physics, Vol. 70, No. 9, 1991, pp. 4665-4670. http://dx.doi.org/10.1063/1.349057

[28] J. Liu, Q. Deng and Y. C. Jean, "Free-Volume Distributions of Polystyrene Probed by Positron-AnnihilationComparison with Free-Volume Theories," Macromolecules, Vol. 26, No. 26, 1993, pp. 7149-7155. http://dx.doi.org/10.1021/ma00078a006

[29] N. Djourelov and M. Misheva, "Source Correction in Positron Annihilation Lifetime Spectroscopy," Journal of Physics: Condensed Matter, Vol. 8, No. 12, 1996, pp. 2081-2087. http://dx.doi.org/10.1088/0953-8984/8/12/020

[30] G. Dlubek, J. Stejny, Th. Lu. Pke, D. Bamford, K. Petters, Ch. Hu. Bner, M. A. Alam and M. J. Hill, "Free-Volume Variation in Polyethylenes of Different Crystallinities: Positron Lifetime, Density, and X-Ray Studies," Journal of Polymer Science Part B: Polymer Physics, Vol. 40, No. 1, 2002, pp. 65-81. http://dx.doi.org/10.1002/polb.10072

[31] O. Shpotyuk, A. Ingram, H. Klym, M. Vakiv, I. Hadzaman and J. Filipecki, "PAL Spectroscopy in Application to Humidity-Sensitive $\mathrm{MgAl}_{2} \mathrm{O}_{4}$ Ceramics," Journal of the European Ceramic Society, Vol. 25, No. 12, 2005, pp. 2981-2984.

http://dx.doi.org/10.1016/i.jeurceramsoc.2005.03.174
[32] A. Barbu, A. Dunlop, D. A. Hardouin, G. Jaskierowicz and N. Lorenzelli, "Microstructural Modifications Induced by Swift Ions in the NiTi Intermetallic Compound," $\mathrm{Nu}$ clear Instruments and Methods in Physics Research Section B: Beam Interactions with Materials and Atoms, Vol. 145, No. 3, 1998, pp. 354-372.

http://dx.doi.org/10.1016/S0168-583X(98)00408-X

[33] E. Goo, A. Murthy and C. J. D. Hetherington, "Preferential Amorphitization of NiTi Alloys at Twin Boundaries by Electron Irradiation," Scripta Metallurgica et Materialia, Vol. 29, No. 4, 1993, pp. 553-555. http://dx.doi.org/10.1016/0956-716X(93)90164-N

[34] A. M. Al-Karmi, "Impedance Spectroscopy of GammaIrradiated PM-355," Radiation Measurements, Vol. 41, No. 2, 2006, pp. 209-212. http://dx.doi.org/10.1016/j.radmeas.2005.07.023

[35] F. Abu-Jarad, A. M. Hala, M. Farhat and M. Islam, "Effect of High Gamma Dose on the PADC Properties," Radiation Measurements, Vol. 28, No. 1-6, 1997, pp. 111114.

[36] T. Suzuki, Y. Ito, K. Kondo, E. Hamada and Y. Ito, "Radiation Effect on Positronium Formation in Low-Temperature Polyethylene," Radiation Physics and Chemistry, Vol. 58, No. 5-6, 2000, pp. 485-489. http://dx.doi.org/10.1016/S0969-806X(00)00204-8

[37] T. Suzuki, T. Miura, Y. Oki, M. Numajiri, K. Kondo and Y. Ito, "Positron Irradiation Effects on Polypropylene and Polyethylene Studied by Positron Annihilation," Radiation Physics and Chemistry, Vol. 45, No. 4, 1995, pp. 657-663. http://dx.doi.org/10.1016/0969-806X(94)E0030-M

[38] J. F. Medel, F. Garcia-Alvarez, E. Gomez-Barrena and J. A. Puertolas, "Microstructure Changes of Extruded Ultra High Molecular Weight Polyethylene after Gamma Irradiation and Shelf-Aging," Polymer Degradation and Stability, Vol. 88, No. 3, 2005, pp. 435-443.

http://dx.doi.org/10.1016/j.polymdegradstab.2004.11.015 